\title{
Article
}

\section{Prevention of Depression in Children, Adolescents, and Young Adults: The Role of Teachers and Parents}

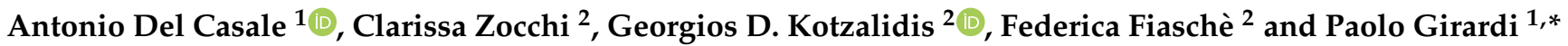 \\ 1 Department of Dynamic and Clinical Psychology, and Health Studies, Faculty of Medicine and Psychology, \\ Sapienza University, 00189 Rome, Italy; antonio.delcasale@uniroma1.it \\ 2 Faculty of Medicine and Psychology, Sapienza University, 00189 Rome, Italy; \\ clarissa.zocchi@uniroma1.it (C.Z.); giorgio.kotzalidis@uniroma1.it (G.D.K.); \\ federica.fiasche@uniroma1.it (F.F.) \\ * Correspondence: paolo.girardi@uniroma1.it
}

Citation: Del Casale, A.; Zocchi, C.; Kotzalidis, G.D.; Fiaschè, F.; Girardi, P. Prevention of Depression in Children Adolescents, and Young Adults: The Role of Teachers and Parents.

Psychiatry Int. 2021, 2, 353-364. https://doi.org/10.3390/ psychiatryint 2030027

Academic Editor: Antonio Narzisi

Received: 19 July 2021

Accepted: 16 August 2021

Published: 1 September 2021

Publisher's Note: MDPI stays neutral with regard to jurisdictional claims in published maps and institutional affiliations.

Copyright: (c) 2021 by the authors. Licensee MDPI, Basel, Switzerland. This article is an open access article distributed under the terms and conditions of the Creative Commons Attribution (CC BY) license (https:// creativecommons.org/licenses/by/ $4.0 /)$.
Abstract: Major depressive disorder (MDD) and other affective disorders may surreptitiously arise in children and adolescents during their school period and impair their social and educational functioning. Besides the social and personal burden, which are increased during the SARS-CoV-2 pandemic, the onset of depression may compromise the future of the growing person with chronicity and recurrence. In this context, educators' training is essential to detect early the onset of a depressive disorder, to spare later consequences through the timely establishment of adequate treatment. The educational staff should receive adequate training to be able to work closely with healthcare providers and parents, thus directing the young person with an affective disorder to the right psychological and pharmacological treatment provider, i.e., a specialized psychologist or psychiatrist. The first approach should be to establish a trustful relationship with the adolescent and his/her classmates, to reduce social and self-stigma and inform about mental illness. If symptoms do not subside and the suffering child or adolescent fails to reintegrate within his/her school environment, cognitive-behavioral interventions are recommended that are individual, group, or computer-based. When needed, these should be implemented with individualized pharmacotherapy.

Keywords: major depressive disorder; early detection; early intervention in psychiatry; educational psychology; disruptive mood dysregulation disorder; COVID-19 pandemic

\section{Introduction: Depression from the Biopsychosocial Perspective to the DSM-5}

As with many other psychopathological conditions, major depressive disorder (MDD) has a multifactorial aetiology. The definition of its causes involves the consideration of several factors which cumulatively give rise to a series of signs and symptoms attributable to this disorder. The "biopsychosocial" health model [1] has partially replaced and completed the "biomedical" paradigm, proposing a continuum between personal experiences, interpersonal relationships, and psychological/biological-somatic alterations. According to this model, it is not possible to speak of mental illness without taking into consideration all the different dimensions of the patient's experience. In the case of depression, in addition to the psychological and relational contributing causes, important physiological variations can also be observed. If on the one hand the experience of people, the environment of their upbringing, daily challenges, and relationships with peers and family members play a very important role in maintaining or impairing the psychological balance, on the other, there are real and objective bodily changes that point to a "biology of depression" of its own.

Neural circuits (serotonergic, dopaminergic, noradrenergic, etc.) respond to different neurotransmitters in a chemical view of the brain. Some circuits may appear to be dysfunctional, as a result of biochemical changes or as the cause of them, ensuing in altered brain signal transmission which predisposes to the onset of depressive symptoms. There is evidence that stress raises the risk for depression, also on the basis of neurodevelopmental 
mechanisms, since alterations in cortical areas which are vulnerable to stressors arising during mid-adolescence can predict subsequently developing depressive symptoms [2]. Integrating these models, we may state that the experiences of individuals, with their related psychological aspects, along with pubertal timing and other individual biological risk factors are variably involved in triggering depression [3,4].

Hence depression is not simply an excessive and prolonged sadness, but a relatively stable condition that involves the mind, body, social experience, and relational world of the individual. It can manifest with psychological, somatic, and cognitive symptoms. The most frequent psychological symptoms are depressed mood, decreased interest in recreational activities, work and socializing, apathy, feelings of guilt or ruin, self-blaming, lack of energy, loss of hope, ideas of death, possible alterations in the content of thought that may come to be inaccessible to criticism (guilt and ruin delusions) [5].

So when we talk about depression, we do not refer to a simple disorder "of the mind", but, more globally, to a set of psychological, physical, and biological alterations with different changes in the neural, endocrine, immune, gastrointestinal, and cardiovascular systems, and disturbance of the circadian rhythms of the body [6], for the treatment of which combined psychopharmacological and psychotherapeutic interventions are essential and have shown better efficacy than a single intervention [7-9]. In children and adolescents, early evidence-based drug and/or psychological treatment of the acute episode is essential, aiming to prevent the development of a refractory or treatment-resistant depression, and other clinical issues [10,11].

When the task force of the Fifth Edition of the Diagnostic and Statistical Manual of Mental Disorders (DSM-5) set out to prepare a new edition of the manual, they had inherited the atheoretic approach of the previous two editions; despite remaining loyal to this approach, their declared goal was to identify and classify disorders according to biological markers, such as genetic or biochemical, i.e., to match the phenomena with background biology, phenotype with genotype. After all these years, it became apparent that they barely reached their pursued goal. Early concerns were expressed before [12] and soon after [13] the publication of the DSM-5 in 2013. However, the newly proposed Research Domain Criteria (RDoC) [14] never caught up with investigators, despite being backed by the National Institute of Mental Health, and the DSM- 5 remains a system with which investigators communicate and speak the same language.

According to the DSM-5, a diagnosis of MDD can be made if five or more of the following symptoms are present simultaneously for at least 15 days, i.e., depressed mood for most of the day; marked decrease in interest or pleasure in all, or almost all, activities for most of the day; weight gain, or conversely significant weight loss not due to dieting, or increased or decreased appetite almost every day; insomnia or hypersomnia; psychomotor agitation or slowing; fatigue or lack of energy; excessive or inappropriate feelings of selfesteem or guilt; reduced ability to think or concentrate or indecision; recurrent thoughts of death or recurrent suicidal ideation without a specific plan or a suicide attempt or a specific plan to commit suicide. The combination of these symptoms must also cause distress in social functioning and the symptoms must not be attributable to substance use [5].

\section{The Need for Early Detection and Stigma Reduction}

While depression is still generally regarded as a disorder of adult or advanced age, it is deeply rooted in early experiences. Even in adult patients with MDD, childhood trauma is a characteristic feature $[15,16]$. This points to the need for early detection and treatment of depression since a shorter duration of untreated illness was found to be related to an increased response to treatment and higher remission rates [17]. A longer duration of untreated depressive illness increases the latency to response [18], meaning that much time is lost in sufferance for the patient. Furthermore, a longer untreated illness duration in depression is associated with a longer overall duration of depression, more comorbidity, more severe depressive symptoms [19], and even higher cognitive impairment [20]. Taken together, these data indicate that the best intervention is early detection [21]; in fact, in 
more recent years diagnosticians tend to reduce the untreated illness duration and this was followed by reduced time to first pharmacotherapy [22]. Hence, preventive programs aiming at reducing the duration of untreated depressive illness and depression onset prevention have been implemented [23-25].

Stigma, either self- (internalizing), or social, is closely associated with mental illness, and this does not spare depression [26,27]. People with depressive feelings tend to withdraw socially and thus be perceived as dull by their peers with poorly developed empathic skills [28]. This brings to avoidance by the peers and to feelings of shame and guilt (which are core symptoms of depression) to patients, especially when mental illness is perceived as of genetic origin [29]. The stigma regards both having the depressive condition and having to take drug treatment for it and this may lead to a lack of treatment adherence [30]. Addressing stigma implies changing people's beliefs about mental illness and is essential among youngsters, who have still to develop their empathic skills. Programs and treatments aiming at reducing social and self-stigma are currently implemented and show promise for both stigma reduction and treatment adherence [31].

\section{Depression in Youth and its Impact on Educational Pathways}

Major depressive disorder, especially in youth and adolescence, may manifest anxious symptoms, irritability, and, in extreme cases, aggression towards others. In addition to these, possible alterations of psychomotricity should be kept in mind, which can be goalless and increased (agitation) or decreased (psychomotor retardation). The most typical somatic symptoms are gastrointestinal (constipation), musculoskeletal (joint and muscle pain, which is often chronic), loss of sexual desire, often hair loss, impairment of the sleep-wake cycle (sometimes it is the first reason why the patient seeks help, with the prevalence of central or terminal insomnia) and asthenia (weakness sensation). Melancholia is rare during adolescence, while anhedonia, anergia and fatigue, sleep disturbance, diminished concentration, and suicidal ideation are most frequent. Symptoms of guilt, self-criticism, psychomotor alteration, and appetite/weight changes may characterize more severe types of adolescent depression [32,33]. Cognitive symptoms may manifest as reduced memory, decreased attention, and concentration difficulties. Obsessive-compulsive symptoms, eating pathology, and thought-shape fusion have been related to depressive symptoms in adolescents [4].

In the DSM-5, a new diagnosis, i.e., "Disruptive Mood Dysregulation Disorder" (DMDD), was introduced, which is one of the depressive disorders and can only be diagnosed between the ages of 6 and 18 years. Typically, it manifests with outbursts of anger, verbal or physical aggression, "emotional storms" or excessive irritability, primarily in response to experienced frustrations, but tend to be out of proportion concerning the situation the child or adolescent is experiencing. A central aspect of the DMDD is the incongruence between the contingent experience and the behavioral reactions and emotional expressions [5]. Clinicians should carefully assess the differential diagnosis of DMDD, considering some overlapping clinical features with MDD [34], and shared clinical and biological correlates with unspecified bipolar disorder in young people $[35,36]$.

There is, in addition, another DSM-5 diagnostic category, "Persistent Depressive Disorder" (PDD) or "Dysthymia", which in children and adolescents is manifested by the persistence of a depressed or irritable mood for most of the day, for an entire year (two consecutive years in adults, who typically do not manifest irritability) [5]. This disorder often has an insidious and early onset and may prelude chronicity in adulthood. Recognizing it early can facilitate its management and increase the effectiveness of treatment, thus becoming a protective factor concerning the risk of illness chronicity. The symptoms with which a patient presents with dysthymia are partly overlapping with those of MDD, although they are more nuanced and less pervasive for the person. There are alterations in the sleep-wake cycle, low energy in doing things, low self-esteem, alteration of the need to feed (anorexia/hyperphagia), difficulty in concentrating, and, finally, feelings of hopelessness [5]. 
In young people, MDD, DMDD, and PDD can share several clinical features, and vulnerability factors, including a history of parental depression and adverse life events [34]. Adolescents with MDD manifesting on a PDD (a condition also called double depression), as compared to those with MDD or PDD alone, have an increased risk of longer, more severe and recurrent episodes, more comorbidities, suicidal behavior, and social and functional impairment [32].

Young people with MDD may manifest vegetative symptoms much more than adults, i.e., change in weight and appetite, decrease in energy level, and alterations in the sleepwake cycle with insomnia. These and other nonspecific symptoms, such as recurrent headaches and unexplained musculoskeletal pain, very often remain unrecognized and misunderstood, misinterpreted, or underestimated [37]. It is important to consider if a teenager starts self-isolating, being uncommunicative or depressed; clinicians should be aware that these states can either constitute psychologically healthy aspects of adolescence, or be symptoms of a mood disorder, and may make part of psychosis risk conditions [38-41].

In the scientific literature, there is evidence showing how a careful eye, and, above all, appropriate training of parents and teachers can facilitate symptom recognition and understanding of the difficulties of adolescents, at home and school, and can allow them to take care of the young. In this regard, several studies have observed that a more responsive and well-informed environment also facilitates the ability of those suffering or manifesting psychosocial distress to seek help [42].

\section{Depression in Youth during the SARS-CoV-2 Pandemic}

The pandemic caused by the SARS-CoV-2 virus and the resulting restrictions have, in some circumstances, compromised the mental health of young people. Lockdown periods caused a reorganization of daily routines with removal from the school environment and sports facilities, with a limitation of social life, and all the activities that young could perform outdoor. All this has led to an excessive stress load and an increase in anxiety with, sometimes, deflection of mood that has invaded the life of the child and adolescent and has affected an often-precarious psychophysical balance [43].

Symptoms may directly or indirectly relate to the pandemic event. They may have their onset during the lockdown period or show up later through increased psychological distress [like post-traumatic, depressive, and anxiety symptoms] that may become fullblown even after the end of the pandemic, especially in those vulnerable, genetically predisposed children with existing sociodemographic risk factors. Studies have already highlighted how children responded to stress exactly as expected, i.e., with high rates of anxiety, depression, and post-traumatic symptoms [44].

Although the entire population experienced feelings of fear, distress, and sadness during the period of forced isolation, children and adolescents were probably the most affected due to their vulnerability and are most likely to experience them even after the pandemic ends. Within this framework, there is a need for prevention with possible early intervention aimed at curbing mental health problems that will arise [45].

Schools could play an important role in supporting, recognizing, and understanding suffering, with referral to specialized services; however, there is a need to enforce territorial services for children and adolescents that are more usable and accessible [46], also considering how much the risk of suicide has increased in children and adolescents in this historical period [47]. It is very important to identify preventive strategies, both with the identification of vulnerable groups and with the recognition of new people at risk [48].

\section{Discussion: Prevention of Depression and Stigma in Schools}

The school environment is a very important place for the creation and maintenance of a student's psychophysical well-being, capable of influencing, in different ways, many aspects of a child's and adolescent's life, by providing tools for training and learning, guaranteeing a space where good social relationships can be developed and cultivated, helping to find within oneself a drive towards the pursuit and achievement of goals, teach- 
ing how to deal with everyday problems and knowing when to ask for help. Depression, and depressive disorders in general, can undermine these possibilities for development and insidiously insert themselves into the life of the young person, compromising its school performance and social relations in all respects, with the risk that very often it is misinterpreted and remains unrecognized $[49,50]$.

The recognition of symptoms, already very complex in itself, adds to a widespread and disabling cultural problem represented by social stigma. Unfortunately, even today, mental illness could remain poorly understood, frighten people, and being confronted with it can trigger different reactions, such as nonacceptance and denial, leading to the denigration of those who suffer from it. We can distinguish two types of public- and self-stigma. Public stigma refers to the inability of the environment to accept and live with mental illness. In fact, due to misinformation and a lack of tolerance, often people who interact with this type of discomfort implement an attitude of exclusion and avoidance, resulting in episodes of bullying and violence against the person who suffers. Self-stigma, on the other hand, can be explained as the tendency of the stigmatized person to feel shame, to experience reduced self-esteem, to self-isolate, and therefore very often to find it difficult to ask for help. Both dynamics fuel the difficulty, in this case of the student, in sharing their emotions, consequently undermining his/her ability to process them. Stigma and denigration of the individual with a psychiatric condition are important factors that negatively influence, along with the illness course, the quality of life of the patient and his/her family [51,52]. Furthermore, male adolescents are more subjected to personal stigma whereas females to perceived stigma, which emphasizes gender differences on aspects of stigma that should be considered in planning intervention strategies [53].

It is not uncommon that within the school a teacher may be faced with a student whose performance begins to decline, who gradually becomes increasingly withdrawn into him/herself, thus decreasing relationships with peers. The teacher will likely find the student to be blue or more irritable, with low energy and little desire to be active and participate in daily activities or interact with a student who suddenly begins to be skip school. Those who suffer from MDD very often no longer want to study. However, from a teacher's viewpoint, it is essential to be aware that this alone may not be sufficient to succeed in overcoming difficulties profitably. In fact, in these conditions, there is a decline in attention, difficulty in concentration, and therefore in memory. These alterations in functioning point to cognitive and humoral impairment, from which MDD is developed. Teachers may show difficulties in identifying children with these symptoms, or ascribing these aspects to a mental disorder [50]. Sometimes, this set of changes can remain misunderstood or be interpreted as a lack of will to participate, hostility, or perhaps as an attitude that may refer to a transition phase, such as adolescence. In this complex scenario, it seems necessary to implement a series of training activities aimed at preventing the onset, or the consequences of a depressive-type disorder in students. The caregiver, whether parent or teacher, should be enabled to recognize and understand the emotional turmoil that the young person is facing, thus enhancing acceptance, and lowering social and self-stigma. Furthermore, there is evidence that expanding teachers' depression literacy improves students' literacy and diminishes concerns on stigmatizing beliefs from teachers to students [54].

\subsection{The Role of Teachers and Staff}

The first useful step in this direction could be training to learn how to recognize the so-called "telltale" signs of a student's psychophysical illness. It is good to keep in mind that each symptom observed must then be contextualized concerning the social reality that the child/adolescent is experiencing, to the historical context, and to his/her temperament. Not all changes or behaviors potentially attributable to MDD are in fact manifestations of a pathological condition. Take as an example the case of absenteeism from school, whether permitted by the parent or deliberately decided by the child/adolescent. Repeated absences could be caused either by a difficulty experienced by the student [55] or by manifest disinterest. In these cases, it is of paramount importance to seek to understand 
what is the real motivation that leads the student to avoid school and withdraw from peers. Observe how it is possible to interpret the same behavior in completely different ways, on the one hand, as a symptom attributable to a student's discomfort, on the other hand, as a deliberate choice, which can occur due to disinterest or other various reasons. In such a case, the role of the teacher as a caregiver comes into play. The teacher, if adequately trained, will avoid an immediate and superficial reading of the student's attitude, and will try to understand what the underlying motivations are. Through a reading of the context, they will try to understand what the student is going through, communicate with him and his parents, looking for information and tools to support and reintegrate him/her in the school context. On the contrary, if the teacher faces such an attitude in a hostile and authoritarian way, it could make the student feel misunderstood, risking that he/she withdraws more into him/herself and increasing his/her level of psychosocial discomfort.

For this reason, it is desirable that training programs and courses be instituted, either prompted by individual school councils, or in coordination with national training programs promoted by coordinated activities of national healthcare systems. In post-war Europe, the idea of instituting medical-psycho-pedagogic units in each school was strong [55] and in Italy received further impulse towards its realization by the psychiatric reform of 1978 [56]. However, since the Italian national healthcare system was later corporatized, such units were no more instituted. Some Italian universities still possess medical-psycho-pedagogic institutes and may carry on autonomously enlightenment programs for psychiatric matters, but a coordinated state effort is lacking. In these institutes, all forces bring forth their experiences and coordination with students' parents is essential to spread knowledge. Organizing educational cine-forums and subsequent debates, where students themselves provide first-person accounts, would do much for this aim. The institution of such programs in other countries resulted in increased knowledge about mental illness [57,58]. Particularly during the pandemic, employing psychologists, physicians and rehabilitators in schools would allow students needing help to refer to appropriate community services, where they will receive tailored individualized treatment ranging from counselling to psychotherapy to pharmacotherapy.

Recognizing early a mood deflection, a tendency to socially withdraw, or a worsening of school performance is very useful because intervening early by relying on experienced mental health personnel can prevent possible chronicity or the establishment of a depressive disorder with multiple episodes in adulthood. It should be remembered that the onset of a depressive episode or other mental disorder in childhood and adolescence may correlate with functional impairment in several domains, including the cognitive, which is likely to persist into adulthood [59]. For this reason, teachers should have clear some concepts of the biopsychosocial approach and the DSM- 5 criteria for depression and other mental disorders, like attention-deficit/hyperactivity disorder (ADHD), which is well represented in school samples and often comorbid with affective disorders.

Another risk, in addition to chronicity, is the burden that this disorder can exert on the individual's existence. In this regard, it is important to emphasize how in different areas [school, work, relationships, and sports] people are called to invest a lot of psychophysical energy every day to achieve increasingly more results, they are pushed to compete in every activity and to put themselves at stake, sometimes to such a point that they are no longer able to adapt to all these demands. This is especially true for young people, who may also lack the necessary tools to face these challenges, overcome possible disappointments and inevitable failures, especially after periods in which they have invested much of their energy and skills [7].

Underestimating the fragility of young people and the burden to which they are subjected daily, even unconsciously, in the different contexts to which they endeavour, can lead to tragic outcomes. According to the World Health Organization, MDD, in its most severe forms, can become fertile ground for suicidal ideation and attempts. To date, suicide is the second leading cause of death in young people between the ages of 15 and 29 [60]. 
Depressive disorders also represent a risk factor for the quality of relational experience, they increase the risk of substance abuse [but can also be induced by it, with alcohol constituting a preeminent example], are related to an increase in antisocial behaviors, and, in the long run, have a negative influence on socio-professional achievement [61]. Substance use and depression have additive effects on adolescent social competence since higher severity of both correlated with lower levels of competence [62]. Furthermore, depression commonly co-occurs with alcohol use disorder, and drinking reduction is associated with a better outcome [63]. Clinicians should carefully investigate alcohol or substance use, and preventative strategies should focus on youth information campaigns on alcohol and substances eventually leading to depression.

Within this framework, one goal is to make the school part of the solution and not part of the problem, creating the basic conditions to transform it into a context capable of observing, recognizing, and intervening in these disorders from a prevention perspective. To facilitate the acquisition of tools by school personnel and parents, real preventive programs should be developed to promote the ability to accept and take charge of situations of discomfort that may arise. School is one of the main environments of socialization and education for almost all children and adolescents. For this reason, it is also necessary to implement relational skills, to facilitate dialogue with students, families, and community services. To correctly interpret their social mandate, teachers, besides refining teaching, should devote themselves to the strengthening of an educational culture aimed at guaranteeing the global well-being of their students, following the principles of the biopsychosocial model.

\subsection{The Role of Parents}

The role of parents should not be underestimated in this respect. Teachers and school psychologists and psychiatrists should be always in contact with parents of students with academic performance problems. Some parents could have psychiatric problems themselves and these may impact their children's behavior outside of the home. The school is one of these structures where the first assessment of undetected psychological distress involving the entire family may occur. Parents may lack adequate psychiatric literacy, and this should be provided by public health agencies, educational courses, and school staff. The current situation is not ideal; teachers have admitted not to have sufficient knowledge of mental illness to be able to deal with pathological parents [64]. Teachers should be aware that school performance is also related to stimuli children receive in their family environment, and parents should realize that their children's inadequacy is not disjointed from what they are doing at home. The collaboration between parents and teachers is therefore fundamental both for the purposes of the prevention and early intervention in MDD.

\subsection{Teacher and Staff Collaboration with Parents}

The well-trained staff should always evaluate parents' psychiatric literacy, as most often students' behavior at school reflects the situation at home. School officials' collaboration with parents is essential in finding a common language in communication, as their perception about students' problems does not match quite [65].

An adequate competence to respond to these requests should include, as a first step, the ability to assess what are the main psychosocial risk factors, both present, and past, like the presence of family conflicts, having suffered episodes of bullying, physical, sexual or emotional abuse, the presence of concomitant disorders, the more or less frequent use of drugs or alcohol, any family history of depression. It is also important to know if there have been episodes in the student's life of loss of loved ones, and consequently to be aware of what are the natural times of the grief process. Ethnic and cultural factors, such as refugee status, are not secondary. Finally, the complexity of the developmental experience within institutional contexts or in the case of adoption is well known and should not be underestimated in the relationship with students. All providers within the school should 
be trained in listening and communication skills so that they can manage the onset of acute sadness and episodes of distress that children and youth frequently experience [66].

The assessment of the student should always be comprehensive, including communication with the family to investigate the possible family psychiatric history and the possible presence of life events that may impact the student's quality of life. School personnel, through this type of observation tools, could in some situations refer the student to qualified personnel who would assess the clinical severity and thus have the possibility of setting up a personalized and targeted therapeutic path. It should be noted that within the 2019 guidelines of the National Institute for Health and Care Excellence, the importance of proper and meticulous training of school staff to recognize risk factors for the development of depressive symptomatology is emphasized [66]. The ability to carefully observe and communicate with the student is an essential starting point for the approach to depressive disorders. Teachers need to be trained and supported by highly qualified staff who can provide them with guidance and supervision to ensure their good caregiver performance. Putting in place a good psychoeducational campaign, with informational and educational intent, does indeed allow school staff and students to become more aware of the recognition and understanding of mental illness [67].

The use of universal or selective preventive approaches may reduce the occurrence of mental illness in young people. Selective approaches [including exercise], which consider familial vulnerability and nongenetic risk exposures, and psychological/psychoeducational interventions could improve anxiety-depressive symptoms [67]. Universal public health approaches, on the other hand, that target school climate or social determinants (demographic, economic, neighbourhood, environmental, social/cultural) of mental disorders may intervene to reduce the risk profile of the population [67].

In addition to providing screening and intervention criteria to teachers and parents, it would be useful to dedicate a training space to students as well, to increase awareness of the illness and to make them understand the importance of asking for help, also facilitating the overcoming of stigma. There is evidence that working with secondary school students, using interactive lesson plans (sharing educational materials, clinical cases, and experiences in psychiatric settings), significantly reduced their stigma toward psychiatric illness [52]. Therefore, the goal should be to educate healthcare personnel and students so that they are enabled to live with people with mental illness, and recognize risk factors and characteristic symptoms; also, they should both be encouraged to seek help from qualified personnel. All this will likely improve children and adolescents' physical and psychological wellbeing, thus enhancing their academic performance. This assumes special importance during the COVID-19 pandemic and its restrictions, given that these restrictions negatively affected school function and students' personal lives. The prevalence of depression and anxiety during the pandemic is high among students, with about half showing depressive symptoms [68], and this has been partially attributed to social isolation and online education constraints [69].

\section{Treatment Tips and Strategies}

To facilitate communication between school personnel and social and health professionals, including psychologists and psychiatrists, it is important to know what the treatments of choice for these disorders are. As for possible therapies, the NICE guidelines propose different programs, depending on the severity of symptoms and the age of the patient. More specifically, the management of mild forms of depression involves different types of approaches, to be chosen according to the assessment of individual situations. A first indication is the implementation of a "watchful waiting" attitude, in which the professional monitors the young person and makes a reassessment after about two weeks. If, on the other hand, he/she believes that it would be appropriate to intervene immediately, different psychotherapeutic paths could be undertaken based on the context, clinical manifestations, level of maturity of the individual, and any comorbidities or neurodevelopmental disorders. For children and adolescents aged 5 to 18 years, the preferred addresses 
would be cognitive-behavioral psychotherapy (either in individual or group modalities, or through digital tools), interpersonal group therapy, and nondirective supportive group therapy [67].

In the case of a diagnosis of moderate-to-severe depression, however, NICE guidelines recommend a different approach. For children between 5 and 11 years of age, other therapeutic paths are preferred. These include family therapy, interpersonal family therapy, psychodynamic psychotherapy, and finally individual cognitive-behavioral therapy. In adolescence, the indications are to start with a three-month intervention of cognitivebehavioral psychotherapy, and if it is not sufficiently effective, to choose another therapeutic path among the following: interpersonal therapy, family therapy (attachment-based or systemic), brief psychosocial intervention, or psychodynamic psychotherapy. During the COVID-19 pandemic, depression and anxiety peaked in students and they could be eased through providing information and psychotherapy [70]. Self-guided, computerbased cognitive-behavioral psychotherapy proved to be effective in reducing depressive symptoms during the COVID-19 pandemic [71]. In cases of no or insufficient response to psychological interventions and more complex situations, psychotherapy requires integration with pharmacological treatments $[8,67]$.

\section{Conclusions}

The school environment can become a context of prevention for mental illness, particularly for depressive disorders. It is highlighted how these discomforts can affect a student's academic performance and can compromise its functioning, its ability to socialize, and more globally its psychophysical well-being. The goal to be achieved is to make school personnel, through specific training, able to identify students at risk, to carry out an initial screening, to promote a greater understanding of mental illness, and to provide a space for listening, thus breaking down the social stigma. Informing young people about the increased risk of depression with alcohol and substance use plays a key role in preventing it. Enhanced teacher and psychology staff communication with parents during the COVID-19 pandemic will possibly overcome the obstacles to wellbeing posed by the restrictions.

Early recognition of students at risk or already suffering from depressive disorder allows for referral to specialized staff and immediate intervention. Making this happen is very important to try to prevent a chronic disease or the triggering of a disorder characterized by a succession of depressive episodes in adulthood. To achieve these results, the school should be part of a wider network of collaboration and dialogue with families and specialized territorial services, also becoming a node of referral to qualified personnel.

Author Contributions: Conceptualization, A.D.C., C.Z. and P.G.; methodology, G.D.K. and F.F.; investigation A.D.C., C.Z., G.D.K. and F.F.; writing-original draft preparation, A.D.C., C.Z. and P.G.; writing-review and editing, G.D.K., C.Z. and F.F.; supervision, P.G., A.D.C. and G.D.K. All authors have read and agreed to the published version of the manuscript.

Funding: This research received no external funding.

Data Availability Statement: Not applicable.

Acknowledgments: Authors gratefully acknowledge the contribution of Mimma Ariano, Ales Casciaro, Teresa Prioreschi, and Susanna Rospo, Librarians of the Sant'Andrea Hospital, School of Medicine and Psychology, Sapienza University, Rome, for rendering precious bibliographic material accessible.

Conflicts of Interest: The authors declare no conflict of interest.

\section{References}

1. Engel, G.L. The need for a new medical model: A challenge for biomedicine. Science 1977, 196, 129-136. [CrossRef] [PubMed]

2. Ho, T.C. Stress and neurodevelopment in adolescent depression. Biol. Psychiatry 2019, 86, e33-e35. [CrossRef]

3. Benoit, A.; Lacourse, E.; Claes, M. Pubertal timing and depressive symptoms in late adolescence: The moderating role of individual, peer, and parental factors. Dev. Psychopathol. 2013, 25, 455-471. [CrossRef] 
4. Pullmer, R.; Zaitsoff, S.L.; Coelho, J.S. Cognitive and behavioral correlates of depressive symptoms in a community sample of adolescents. Clin. Child. Psychol. Psychiatry 2020, 25, 98-105. [CrossRef]

5. American Psychiatric Association. Diagnostic and Statistical Manual of Mental Disorders, 5th ed.; (DSM-5); American Psychiatric Association: Arlington, VA, USA, 2013.

6. Blake, M.J.; Trinder, J.A.; Allen, N.B. Mechanisms underlying the association between insomnia, anxiety, and depression in adolescence: Implications for behavioral sleep interventions. Clin. Psychol. Rev. 2018, 63, 25-40. [CrossRef]

7. Biondi, M. Compendio di Psichiatria e Salute Mentale; Alpes Italia: Rome, Italy, 2016.

8. Brugnoli, R.; Girardi, P. Manuale di Farmacoterapia Psichiatrica; Pacini Editore: Pisa, Italy, 2012.

9. Tatarelli, R. Psichiatria per Problemi; Giovanni Fioriti Editore: Rome, Italy, 2006.

10. DeFilippis, M.; Wagner, K.D. Management of treatment-resistant depression in children and adolescents. Paediatr. Drugs 2014, 16, 353-361. [CrossRef]

11. Weersing, V.R.; Jeffreys, M.; Do, M.T.; Schwartz, K.T.; Bolano, C. Evidence base update of psychosocial treatments for child and adolescent depression. J. Clin. Child. Adolesc. Psychol. 2017, 46, 11-43. [CrossRef]

12. Insel, T.; Cuthbert, B.; Garvey, M.; Heinssen, R.; Pine, D.S.; Quinn, K.; Sanislow, C.; Wang, P. Research domain criteria (RDoC): Toward a new classification framework for research on mental disorders. Am. J. Psychiatry 2010, 167, 748-751. [CrossRef] [PubMed]

13. Casey, B.J.; Oliveri, M.E.; Insel, T. A neurodevelopmental perspective on the research domain criteria (RDoC) framework. Biol. Psychiatry 2014, 76, 350-353. [CrossRef]

14. Insel, T.R. The NIMH Research Domain Criteria (RDoC) Project: Precision medicine for psychiatry. Am. J. Psychiatry 2014, 171, 395-397. [CrossRef] [PubMed]

15. Kuzminskaite, E.; Vinkers, C.H.; Elzinga, B.M.; Wardenaar, K.J.; Giltay, E.J.; Penninx, B.W.J.H. Childhood trauma and dysregulation of multiple biological stress systems in adulthood: Results from the Netherlands Study of Depression and Anxiety (NESDA). Psychoneuroendocrinology 2020, 121, 104835. [CrossRef]

16. Fan, J.; Liu, W.; Xia, J.; Li, S.; Gao, F.; Zhu, J.; Han, Y.; Zhou, H.; Liao, H.; Yi, J.; et al. Childhood trauma is associated with elevated anhedonia and altered core reward circuitry in major depression patients and controls. Hum. Brain Mapp. 2021, 42, $286-297$. [CrossRef]

17. Ghio, L.; Gotelli, S.; Marcenaro, M.; Amore, M.; Natta, W. Duration of untreated illness and outcomes in unipolar depression: A systematic review and meta-analysis. J. Affect. Disord. 2014, 152-154, 45-51. [CrossRef] [PubMed]

18. De Diego-Adeliño, J.; Portella, M.J.; Puigdemont, D.; Pérez-Egea, R.; Alvarez, E.; Pérez, V. A short duration of untreated illness (DUI) improves response outcomes in first-depressive episodes. J. Affect. Disord. 2010, 120, 221-225. [CrossRef] [PubMed]

19. Menculini, G.; Verdolini, N.; Brufani, F.; Pierotti, V.; Cirimbilli, F.; Di Buò, A.; Spollon, G.; De Giorgi, F.; Sciarma, T.; Tortorella, A.; et al. Comorbidities, depression severity, and circadian rhythms disturbances as clinical correlates of duration of untreated illness in affective disorders. Medicina 2021, 57, 459. [CrossRef] [PubMed]

20. Galimberti, C.; Bosi, M.F.; Volontè, M.; Giordano, F.; Dell'Osso, B.; Viganò, C.A. Duration of untreated illness and depression severity are associated with cognitive impairment in mood disorders. Int. J. Psychiatry Clin. Pract. 2020, 24, 227-235. [CrossRef] [PubMed]

21. Rasing, S.P.A.; Spijker, J.; Stikkelbroek, Y.A.J.; Creemers, D.H.M. De beste behandeling voor depressie is vroegsignalering en preventie bij jeugdigen [The best intervention for depression is early detection and prevention in youth]. Tijdschr. Psychiatr. 2021, 63, 111-114. [PubMed]

22. Dell'Osso, B.; Cremaschi, L.; Grancini, B.; De Cagna, F.; Benatti, B.; Camuri, G.; Arici, C.; Dobrea, C.; Oldani, L.; Palazzo, M.C.; et al. Italian patients with more recent onset of Major Depressive Disorder have a shorter duration of untreated illness. Int. J. Clin. Pract. 2017, 71. [CrossRef]

23. Picardi, A.; Lega, I.; Tarsitani, L.; Caredda, M.; Matteucci, G.; Zerella, M.P.; Miglio, R.; Gigantesco, A.; Cerbo, M.; Gaddini, A.; et al. A randomised controlled trial of the effectiveness of a program for early detection and treatment of depression in primary care. J. Affect. Disord. 2016, 198, 96-101. [CrossRef]

24. Aguilar-Latorre, A.; Navarro, C.; Oliván-Blázquez, B.; Gervilla, E.; Magallón Botaya, R.; Calafat-Villalonga, C.; García-Toro, M.; Boira, S.; Serrano-Ripoll, M.J. Effectiveness and cost-effectiveness of a lifestyle modification programme in the prevention and treatment of subclinical, mild and moderate depression in primary care: A randomised clinical trial protocol. BMJ Open 2020, 10, e038457. [CrossRef]

25. Rith-Najarian, L.R.; Chorpita, B.F.; Gong-Guy, E.; Hammons, H.R.; Chavira, D.A. Feasibility of a web-based program for universal prevention of anxiety and depression in university students: An open trial. J. Am. Coll. Health 2021; Epub ahead of print. [CrossRef]

26. Park, S.; Kim, M.J.; Cho, M.J.; Lee, J.Y. Factors affecting stigma toward suicide and depression: A Korean nationwide study. Int. J. Soc. Psychiatry 2015, 61, 811-817. [CrossRef]

27. Chen, J.A.; Shapero, B.G.; Trinh, N.T.; Chang, T.E.; Parkin, S.; Alpert, J.E.; Fava, M.; Yeung, A.S. Association between stigma and depression outcomes among Chinese immigrants in a primary care setting. J. Clin. Psychiatry 2016, 77, e1287-e1292. [CrossRef] [PubMed]

28. Suwalska, J.; Suwalska, A.; Neumann-Podczaska, A.; Łojko, D. Medical students and stigma of depression. Part I. Stigmatization of patients. Psychiatr. Pol. 2016, 51, 495-502. [CrossRef] [PubMed] 
29. Rüsch, N.; Todd, A.R.; Bodenhausen, G.V.; Corrigan, P.W. Biogenetic models of psychopathology, implicit guilt, and mental illness stigma. Psychiatry Res. 2010, 179, 328-332. [CrossRef]

30. Sedlácková, Z.; Kamarádová, D.; Prásko, J.; Látalová, K.; Ocisková, M.; Ocisková, M.; Cinculová, A.; Kubínek, R.; Mainerová, B.; Tichácková, A.; et al. Treatment adherence and self-stigma in patients with depressive disorder in remission-A cross-sectional study. Neuroendocrinol. Lett. 2015, 36, 171-177.

31. Tong, P.; Bu, P.; Yang, Y.; Dong, L.; Sun, T.; Shi, Y. Group cognitive behavioural therapy can reduce stigma and improve treatment compliance in major depressive disorder patients. Early Interv. Psychiatry 2020, 14, 172-178. [CrossRef] [PubMed]

32. Parker, G.; Roy, K. Adolescent depression: A review. Aust. N. Z. J. Psychiatry 2001, 35, 572-580. [CrossRef] [PubMed]

33. Patton, G.C.; Coffey, C.; Posterino, M.; Carlin, J.B.; Wolfe, R. Adolescent depressive disorder: A population-based study of ICD-10 symptoms. Aust. N. Z. J. Psychiatry 2000, 34, 741-747. [CrossRef] [PubMed]

34. Benarous, X.; Renaud, J.; Breton, J.J.; Cohen, D.; Labelle, R.; Guilé, J.M. Are youths with disruptive mood dysregulation disorder different from youths with major depressive disorder or persistent depressive disorder? J. Affect. Disord. 2020, 265, 207-215. [CrossRef]

35. Fristad, M.A.; Wolfson, H.; Algorta, G.P.; Youngstrom, E.A.; Arnold, L.E.; Birmaher, B.; Horwitz, S.; Axelson, D.; Kowatch, R.A.; Findling, R.L.; et al. Disruptive mood dysregulation disorder and bipolar disorder not otherwise specified: Fraternal or identical twins? J. Child. Adolesc. Psychopharmacol. 2016, 26, 138-146. [CrossRef] [PubMed]

36. Linke, J.O.; Adleman, N.E.; Sarlls, J.; Ross, A.; Perlstein, S.; Frank, H.R.; Towbin, K.E.; Pine, D.S.; Leibenluft, E.; Brotman, M.A. White matter microstructure in pediatric bipolar disorder and disruptive mood dysregulation disorder. J. Am. Acad. Child. Adolesc. Psychiatry 2020, 59, 1135-1145. [CrossRef]

37. Rice, F.; Riglin, L.; Lomax, T.; Souter, E.; Potter, R.; Smith, D.J.; Thapar, A.K.; Thapar, A. Adolescent and adult differences in major depression symptom profiles. J. Affect. Disord. 2019, 243, 175-181. [CrossRef] [PubMed]

38. Fusar-Poli, P.; Nelson, B.; Valmaggia, L.; Yung, A.R.; McGuire, P.K. Comorbid depressive and anxiety disorders in 509 individuals with an at-risk mental state: Impact on psychopathology and transition to psychosis. Schizophr. Bull. 2014, 40, 120-131. [CrossRef] [PubMed]

39. Beck, K.; Andreou, C.; Studerus, E.; Heitz, U.; Ittig, S.; Leanza, L.; Riecher-Rössler, A. Clinical and functional long-term outcome of patients at clinical high risk (CHR) for psychosis without transition to psychosis: A systematic review. Schizophr. Res. 2019, 210, 39-47. [CrossRef] [PubMed]

40. Joa, I.; Bjornestad, J.; Johannessen, J.O.; Langeveld, J.; Stain, H.J.; Weibell, M.; Hegelstad, W.T.V. Early detection of ultra high risk for psychosis in a Norwegian catchment area: The two year follow-up of the prevention of psychosis study. Front. Psychiatry 2021, 12, 573905. [CrossRef]

41. Rodríguez-Pascual, M.; Álvarez-Subiela, X.; Tor, J.; Pardo, M.; de la Serna, E.; Sugranyes, G.; Puig, O.; Baeza, I.; Dolz, M. Major depressive disorder and attenuated negative symptoms in a child and adolescent sample with psychosis risk syndrome: The CAPRIS study. Eur. Child. Adolesc. Psychiatry 2021. [CrossRef]

42. Townsend, L.; Musci, R.; Stuart, E.; Ruble, A.; Beaudry, M.B.; Schweizer, B.; Owen, M.; Goode, C.; Johnson, S.L.; Bradshaw, C.; et al. The Association of School Climate, Depression Literacy, and Mental Health Stigma among High School Students. J. Sch. Health 2017, 87, 567-574. [CrossRef] [PubMed]

43. De Figueiredo, C.S.; Sandre, P.C.; Portugal, L.C.L.; Mázala-de-Oliveira, T.; da Silva Chagas, L.; Raony, Í.; Ferreira, E.S.; Giestal-de-Araujo, E.; Dos Santos, A.A.; Bomfim, P.O. COVID-19 pandemic impact on children and adolescents' mental health: Biological, environmental, and social factors. Prog. Neuropsychopharmacol. Biol. Psychiatry 2021, 106, 110171. [CrossRef] [PubMed]

44. Marques de Miranda, D.; da Silva Athanasio, B.; Sena Oliveira, A.C.; Simoes-E-Silva, A.C. How is COVID-19 pandemic impacting mental health of children and adolescents? Int. J. Disaster Risk Reduct. 2020, 51, 101845. [CrossRef] [PubMed]

45. Loades, M.E.; Chatburn, E.; Higson-Sweeney, N.; Reynolds, S.; Shafran, R.; Brigden, A.; Linney, C.; McManus, M.N.; Borwick, C.; Crawley, E. Rapid systematic review: The impact of social isolation and loneliness on the mental health of children and adolescents in the context of COVID-19. J. Am. Acad. Child. Adolesc. Psychiatry 2020, 59, 1218-1239.e3. [CrossRef]

46. Singh, S.; Roy, D.; Sinha, K.; Parveen, S.; Sharma, G.; Joshi, G. Impact of COVID-19 and lockdown on mental health of children and adolescents: A narrative review with recommendations. Psychiatry Res. 2020, 293, 113429. [CrossRef] [PubMed]

47. Thompson, E.C.; Thomas, S.A.; Burke, T.A.; Nesi, J.; MacPherson, H.A.; Bettis, A.H.; Kudinova, A.Y.; Affleck, K.; Hunt, J.; Wolff, J.C. Suicidal thoughts and behaviors in psychiatrically hospitalized adolescents pre- and post-COVID-19: A historical chart review and examination of contextual correlates. J. Affect. Disord. Rep. 2021, 4, 100100. [CrossRef]

48. Wasserman, D.; Iosue, M.; Wuestefeld, A.; Carli, V. Adaptation of evidence-based suicide prevention strategies during and after the COVID-19 pandemic. World Psychiatry 2020, 19, 294-306. [CrossRef] [PubMed]

49. Jaycox, L.H.; Stein, B.D.; Paddock, S.; Miles, J.N.; Chandra, A.; Meredith, L.S.; Tanielian, T.; Hickey, S.; Burnam, M.A. Impact of teen depression on academic, social, and physical functioning. Pediatrics 2009, 124, e596-e605. [CrossRef] [PubMed]

50. Pedersen, M.L.; Holen, S.; Lydersen, S.; Martinsen, K.; Neumer, S.P.; Adolfsen, F.; Sund, A.M. School functioning and internalizing problems in young schoolchildren. BMC Psychol. 2019, 7, 88. [CrossRef] [PubMed]

51. Snyder, M. Changing the tide: Stigma, school youth, and mental illness. NASN Sch. Nurse 2015, 30, 130-132. [CrossRef] [PubMed]

52. Del Casale, A.; Manfredi, G.; Kotzalidis, G.D.; Serata, D.; Rapinesi, C.; Caccia, F.; Caccia, V.; Brugnoli, C.; Caltagirone, S.S.; De Chiara, L.; et al. Awareness and education on mental disorders in teenagers reduce stigma for mental illness: A preliminary study. J. Psychopathol. 2013, 19, 208-212. 
53. Lynch, H.; McDonagh, C.; Hennessy, E. Social anxiety and depression stigma among adolescents. J. Affect. Disord. 2021, 281, 744-750. [CrossRef]

54. Miller, L.; Musci, R.; D'Agati, D.; Alfes, C.; Beaudry, M.B.; Swartz, K.; Wilcox, H. Teacher mental health literacy is associated with student literacy in the Adolescent Depression Awareness Program. Sch. Ment. Health 2019, 11, 357-363. [CrossRef]

55. Levi, S. L'infanzia Anormale e l'Istituto Medico Pedagogico Umberto I [Abnormal Infancy and the Umberto I Medical-Pedagogic Institute]; Tipocalcografia Classica: Florence, Italy, 1954.

56. Consiglio dei Ministri della Repubblica Italiana. Legge 23 dicembre 1978, n. 833. Istituzione del servizio sanitario nazionale. Gazzetta Ufficiale 360, del 28-12-1978-360 Suppl. Ordinario.

57. $\mathrm{Ng}$, P.; Chan, K.F. Attitudes towards people with mental illness. Effects of a training program for secondary school students. Int. J. Adolesc. Med. Health 2002, 14, 215-224. [CrossRef]

58. Oduguwa, A.O.; Adedokun, B.; Omigbodun, O.O. Effect of a mental health training programme on Nigerian school pupils' perceptions of mental illness. Child. Adolesc. Psychiatry Ment. Health 2017, 11, 19. [CrossRef] [PubMed]

59. Finning, K.; Ford, T.; Moore, D.A.; Ukoumunne, O.C. Emotional disorder and absence from school: Findings from the 2004 British Child and Adolescent Mental Health Survey. Eur. Child. Adolesc. Psychiatry 2020, 29, 187-198. [CrossRef]

60. World Health Organization. Depression and Other Common Mental Disorders. Global Health Estimates; World Health Organization: Geneva, Switzerland, 2017.

61. Seeley, J.R.; Stice, E.; Rohde, P. Screening for depression prevention: Identifying adolescent girls at high risk for future depression. J. Abnorm. Psychol. 2009, 118, 161-170. [CrossRef] [PubMed]

62. Becker, S.J.; Curry, J.F. Interactive effect of substance abuse and depression on adolescent social competence. J. Clin. Child. Adolesc. Psychol. 2007, 36, 469-475. [CrossRef]

63. Farré, A.; Tirado, J.; Spataro, N.; Alías-Ferri, M.; Torrens, M.; Fonseca, F. Alcohol Induced Depression: Clinical, Biological and Genetic Features. J. Clin. Med. 2020, 9, 2668. [CrossRef]

64. Bruland, D.; Kornblum, K.; Harsch, S.; Bröder, J.; Okan, O.; Bauer, U. Schüler mit einem psychisch erkrankten Elternteil und die Mental Health Literacy von Lehrkräften [Students having parents with mental health issues and teachers' mental health literacy]. Prax. Kinderpsychol. Kinderpsychiatr. 2017, 66, 774-790. (In German) [CrossRef]

65. De Haan, L.; Boljevac, T. Alcohol use among rural middle school students: Adolescents, parents, teachers, and community leaders' perceptions. J. Sch. Health 2009, 79, 58-66, quiz 90-92s. [CrossRef]

66. National Institute for Health and Care Excellence. Depression in Children and Young People: Identification and Management; National Institute for Health and Care Excellence: London, UK, 2019. Available online: https://www.nice.org.uk/guidance/ng134 (accessed on 27 August 2021).

67. Fusar-Poli, P.; Correll, C.U.; Arango, C.; Berk, M.; Patel, V.; Ioannidis, J.P.A. Preventive psychiatry: A blueprint for improving the mental health of young people. World Psychiatry 2021, 20, 200-221. [CrossRef] [PubMed]

68. Zhang, Z.; Zhai, A.; Yang, M.; Zhang, J.; Zhou, H.; Yang, C.; Duan, S.; Zhou, C. Prevalence of depression and anxiety symptoms of high school students in Shandong Province during the COVID-19 epidemic. Front. Psychiatry 2020, 11, 570096. [CrossRef]

69. AlAzzam, M.; Abuhammad, S.; Abdalrahim, A.; Hamdan-Mansour, A.M. Predictors of depression and anxiety among senior high school students during COVID-19 pandemic: The context of home quarantine and online education. J. Sch. Nurs. 2021, 37, 241-248. [CrossRef]

70. Meng, N.; Liu, Z.; Wang, Y.; Feng, Y.; Liu, Q.; Huang, J.; Li, X. Beyond sociodemographic and COVID-19-related factors: The association between the need for psychological and information support from school and anxiety and depression. Med. Sci. Monit. 2021, 27, e929280. [CrossRef]

71. Detweiler Guarino, I.; Cowan, D.R.; Fellows, A.M.; Buckey, J.C. Use of a self-guided computerized cognitive behavioral tool during COVID-19: Evaluation study. JMIR Form. Res. 2021, 5, e26989. [CrossRef] 